\title{
Understanding Positive Father-Child Interaction: Children's, Fathers', and Mothers' Contributions
}

\author{
Erin K. Holmes \\ Brigham Young University - Provo, erin_holmes@byu.edu
}

Aletha C. Huston

University of Texas at Austin

Follow this and additional works at: https://scholarsarchive.byu.edu/facpub

Part of the Other Social and Behavioral Sciences Commons

\section{Original Publication Citation}

Holmes, E. K., and Huston, A. C. (2010). Understanding positive father-child interaction:

Children's, fathers', and mothers' contributions. Fathering: A Journal of Research, Theory, and

Practice About Men As Fathers, 8(2), 203-225.

\section{BYU ScholarsArchive Citation}

Holmes, Erin K. and Huston, Aletha C., "Understanding Positive Father-Child Interaction: Children's, Fathers', and Mothers' Contributions" (2010). Faculty Publications. 4768.

https://scholarsarchive.byu.edu/facpub/4768

This Peer-Reviewed Article is brought to you for free and open access by BYU ScholarsArchive. It has been accepted for inclusion in Faculty Publications by an authorized administrator of BYU ScholarsArchive. For more information, please contact ellen_amatangelo@byu.edu. 


\section{INTERACTION: CHILDREN's, FATHERS', AND MOTHERS' CONTRIBUTIONS}

Guided by a systemic ecological framework for father involvement, we investigate children's, mothers', and fathers' contributions to observed father-child interaction. Analyses of 586 married resident fathers, their wives, and a target first-grade child (participants in the NICHD Study of Early Child Care) demonstrate that an additive model of father involvement accounts for the quality of father-child interaction better than a model which focuses on only one component of the system. Father parenting beliefs, child language skills, child social skills, maternal employment, and dyadic mother-child interaction quality each additively and significantly contribute to positive father-child interaction. Father average income and education levels relate to dyadic interaction, but individual and family characteristics account for their effects. Moderational analyses resulted in a significant interaction between father parenting beliefs and child social skills, providing preliminary support for the systemic ecological assumption that father-child interaction is better understood in a model that is not only additive but also interactive.

Keywords: fathers, father-child interaction, father-child relations, mother-child relations

Based on a systemic ecological perspective, Doherty and his colleagues posit that a complex mix of factors occurring inside and outside families affect father involvement (Doherty, Kouneski, \& Erickson, 1998). They further argue that no one group of characteristics in isolation can adequately predict father involvement. It is only through the

\footnotetext{
a School of Family Life, Brigham Young University.

b School of Human Ecology, The University of Texas at Austin.

We are grateful to the National Institute of Child Health and Human Development Early Child Care Research Network for designing and carrying out the data collection, and to Ted Huston, Ed Anderson, Ted Dix, Rob Palkovitz, and Alan Hawkins for helpful comments on earlier drafts. This research was supported in part by a grant from the National Institutes of Health (2V10 HD25430-11) to the University of Kansas with a subcontract to The University of Texas at Austin.
}

Correspondence concerning this article should be addressed to Erin K. Holmes, PhD, School of Family Life, Brigham Young University, 2092C JFSB, Provo, UT 84602. Email: erin_holmes@byu.edu 
interrelations of individual, family, and sociodemographic factors across time that one can clearly understand father involvement.

Although many researchers recognize the importance of studying father involvement through a systemic ecological lens, it is rare to find data that can assess the additive effect of the sociodemographic, individual, and dyadic characteristics proposed in an ecological model. As a result, many researchers must focus on only one or two components of this complex model. However, the Eunice Kennedy Shriver NICHD funded, multi-region, longitudinal Study of Early Child Care includes data assessing all such components of a systemic ecological approach to father involvement. Therefore, using data from the Study of Early Child Care, and guided by Doherty et al.'s model, we explore what sociodemographic, individual, and dyadic factors work in tandem to predict father-child interaction at first grade. We further explore potential moderating factors of this association.

\section{Systemic Ecological Approach to Father-Child Interaction}

Doherty and his colleagues (1998) propose that father involvement is best understood using a systemic ecological lens which combines family systems theory with sensitivity to ecological and temporal influences on father involvement. Family systems theory makes three important propositions about family functioning. First, a family is a unit of organized, interdependent individuals. The individuals are best understood in the context of this whole unit, where the functioning of the individuals is related not only to the individuals themselves, but also to the complex system of behaviors within and between members of the system. Thus, if we want to understand father-child interaction, we must consider not only fathers' contributions, but also children's and mothers' contributions to father involvement in the same family context. We employ this theoretical approach by assessing the associations between father-child interaction and individual father, child, and mother characteristics in the same family system.

Second, the family system is not only composed of organized interdependent individuals. It is also composed of interdependent subsystems such as the parental marriage and parent-child relationships. Thus, father involvement is best considered not only in the context of interdependent individual family members, but also in the context of interdependent family subsystems. We therefore include mother-child interaction and marital intimacy in the model to account for the association between family subsystems and the quality of father-child interaction.

Third, family systems theory proposes that family processes are not only additive, but also interactive. The interactive nature of family processes suggests that the effects of fathers, mothers, and children on father-child interaction may vary as a function of each other. From a systemic perspective, these moderating influences create differences in family context which may contribute to varying father-child interactional outcomes. Of the multitude of possible moderating influences within a given family system, we focus our analyses on one key gap in the existing literature: a need to better understand the ways in which individual characteristics of fathers and children modify the quality 
of their interaction in the dyad. We therefore examined the two-way interactions between all father and child characteristics in the model.

Finally, Doherty et al. (1998) add ecological sensitivity to a family systems model emphasizing that families operate within a broader socioeconomic context. Socioeconomic influences such as a family's economic place in society, a parent's educational attainment, ethnicity, and the interplay between employment and family life all impact family functioning. For this reason, we include variables representing these contexts of father-child interaction in our model to better account for the association between social contexts and father-child relationship quality. Below, we highlight literature on the systemic ecological connections between father-child interaction and individual characteristics of fathers, children, and mothers, as well as dyadic characteristics of motherchild interaction and the parental marriage.

\section{Fathers' Contributions to Father-Child Interaction}

Research examining fathers' contributions to father-child interaction has identified numerous characteristics of the father that may shape his interactions with his child. In this brief review, we focus attention on the way that men's parenting attitudes and responsibility for childrearing impact the quality of father-child interaction.

Parenting attitudes. In his systemic view of predictors of parenting, Belsky (1984) posited that a parent's attitudes may affect his competence at childcare tasks, and likely influence childrearing goals, which, in turn, may influence a parent's direct engagement with his or her child. Empirical reports support this association for fathers. Previous research has explored the effects of such attitudes as paternal self efficacy (Bonney, Kelley, \& Levant, 1999), perceptions of the value and purpose of paternal involvement (Beitel \& Parke, 1998; Fagan \& Barnett, 2003), and authoritative versus authoritarian discipline strategies (Gaertner, Spinrad, Eisenberg, \& Greving, 2007) on father involvement. Fathers' parenting attitudes do indeed appear to be meaningful correlates of their parenting behaviors.

Despite these associations between attitudes and father-child interaction, Cabrera, Fitzgerald, Bradley, \& Roggman (2007) report that a man's traditional versus childoriented attitudes are underexplored in the father involvement research literature. We suggest that these more general beliefs are also likely meaningful correlates of fatherchild interaction. For example, if a father holds adult-oriented views of childrearing, which reflect beliefs in firm control of child behavior and strict obedience to adult authority, then he will likely be more emotionally distant and less warm with his child, resulting in lower quality interactions in the dyad. We hypothesize that the more traditional a father's parenting beliefs are, the lower the quality of his interaction with his first grader will be.

Responsibility for childrearing. Responsibility for childrearing includes tasks such as managing and scheduling things in a child's life, and coordinating resources for that 
child. Lamb, Pleck, Charnov and Levine (1985) propose that responsibility for one's child is a critical component of father involvement associated with, but distinct from actual engagement in the father-child relationship. Unfortunately, both quantitative components (such as the amount of a father's responsibility for his child) and qualitative components of father involvement (such as the quality of dyadic interaction between father and child) are less commonly explored in the same models (Parke, 2002). Some suggest that this is because high levels of responsibility for childrearing are assumed to be highly correlated with the quality of involvement. Critics of this assumption suggest a strong need for more research examining the relations between responsibility for care and quality of care. In this paper, we ask the simple question, are father responsibility for child care and father-child interaction positively correlated?

\section{Children's Contributions to Father-Child Interaction}

Since Bell (1968) first argued that children directly and indirectly influence their parents, researchers have studied such child characteristics as sex, birth order, and temperament as predictors of parent-child interaction, parenting behaviors, and parenting beliefs (Levy-Shiff, 1994; NICHD Early Child Care Research Network, 2000; Kelley, Smith, \& Green, 1998). For example, some research suggests that fathers are more engaged with their sons than with their daughters, particularly as children age (Parke, 2002). Further, recent findings suggest that firstborn children receive 20-30 minutes more quality time each day than a second born child from the same family (Price, 2008). Finally, a child's temperament may influence the parent's perception of the child and his perception of himself as a parent. Both of these factors determine how the parentchild relationship will evolve over time (Schoppe-Sullivan, Mangelsdorf, Brown, \& Sokolowski, 2007). Therefore, we include child sex, birth order, and temperament as meaningful correlates of father involvement in our model.

Social skills. Although other child skills such as social skills would be theoretically relevant predictors of father-child interaction patterns (Palkovitz, Marks, Appleby, \& Holmes, 2003), such characteristics are less often investigated as contributors to father-child interaction. One recent exception is a study showing that child sociability positively predicted a father's time with his child, his accessibility to his child, and his responsibility for the child's care (McBride, Schoppe, \& Rane, 2002). For this reason, we include children's social skills in our model, and hypothesize that more socially skilled children (measured at 54 months) will have better interaction quality in the father-child dyad at first grade. By controlling for father-child interaction quality at 54 months, we are better able to consider children's social skills as unique contributors to the nature of dyadic interaction patterns.

Language skills. Children's language skills likely affect father-child interaction. Research on the connection between emerging language skills and infant/toddler synchrony with mothers has laid some foundation for an exploration with fathers. For ex- 
ample, Bronson (1974) observed infant-mother dyads and concluded that as a consequence of the infant's increasing ability to sustain her mother's attention and express infant needs, the mother improved her own contact with the baby. We expect child language skills to enhance father-child interaction. By controlling for father-child interaction quality at 54 months, we are also better able to consider children's language skills as unique contributors to father-child interaction at first grade.

\section{Mothers' Contributions to Father-Child Interaction}

According to a systemic ecological model, characteristics of one member of the group affect characteristics and patterns of other members because individuals within the family fill roles, follow rules, and create communication patterns specific to the family group. Research on maternal predictors of father involvement support this claim. A mother's need for maternal identity confirmation (Allen \& Hawkins, 1999), her attitudes about the father's role (Palkovitz, 1984), her beliefs about the gendered differentiation of family roles (Fagan \& Barnett, 2003), and her appraisal of the father's parenting skills (Beitel \& Parke, 1998) all influence father involvement. Though the connection between a variety of maternal attitudes and father involvement is being established, mixed findings exist regarding the association between maternal employment and father-child interaction.

Maternal employment. Maternal employment characteristics, particularly the number of hours worked, are associated with the quantity of father involvement (Grych \& Clark, 1999; McBride, et al., 2002; NICHD Early Child Care Research Network, 2000). Evidence regarding maternal employment and the quality of father-child interaction is more mixed. Clarke-Stewart, Gruber, and Fitzgerald (1994) reported that maternal employment was not related to the quality or style of paternal behavior in their sample, while Barnett and Gareis (2007) found that women's work schedules had differing effects on father involvement. Fathers whose wives worked in the evening reported better parenting skills and better knowledge about their children's daily lives than did fathers whose wives worked day shifts. Belsky (1999), however, found that fathers of firstborn sons provided less sensitive, affectionate, and involved care for their sons during home observations (from 15 through 33 months) when their boys were in nonparental care for more hours, presumably because of mothers' employment.

Considering these mixed findings in a systemic ecological framework, we suggest that the effects of maternal employment on father-child interaction probably depend on parents' attitudes and beliefs; using the number of hours alone may miss important individual variations in father involvement due to maternal employment. In this model, we pair maternal employment hours with the father's satisfaction with maternal employment and mother's beliefs about the effect of maternal employment on child development to better contextualize the role of maternal employment on other systemic ecological aspects of father-child interaction. 
Mother-child interaction. Most models examining correlations between fatherchild interaction and child outcomes include a measure of mother-child interaction with the assumption that mother-child interaction and father-child interaction within the same family will be linked (Pleck \& Masciadrelli, 2004). A systemic approach would support this link as both are associated through the parent-child subsystem. Unfortunately, research directly examining the relationship between mother-child interaction and father-child interaction is sparse (Marsiglio, Amato, Day, \& Lamb, 2000). To address this limitation, we test for direct relations between the two.

Two competing hypotheses about the nature of the association between motherchild interaction and father-child interaction exist. A complementarity hypothesis would suggest a positive association between the two, based on the general assumption that a common emotional climate of positivity or negativity in the family would impact both the mother-child and the father-child dyad in similar ways. A compensatory hypothesis would suggest a negative association between mother-child interaction and fatherchild interaction, where a lack of quality interaction in one dyad may lead the other parent, the child, or both to increasingly focus attention on each other to make up for the lower quality interaction with the other parent. Thus, as we test for direct effects between the two, we also seek to establish which hypothesis about the association is better supported by these data.

\section{The Parental Marriage and Father-Child Interaction}

Finally, based on a systemic ecological view, the quality of the relationship in the spousal subsystem is likely to influence the quality of the parent-child relationship. Research has established a clear connection between marital quality and father-child interaction (for review see Cummings, Goeke-Morey, \& Raymond, 2004). When marital quality is low, father-child interaction is also likely to be low. This association may reflect couple specific processes in the marriage, or may be more specific to conflict in the parenting alliance (McBride \& Rane, 1998). While discovering detailed processes between marriage, coparenting, and parenting is not possible given limitations in the secondary data set we use for these analyses, Doherty et al. (1998) suggest in their model that father-child relationships are more susceptible to variability in marriage than mother-child relationships are; thus, we expect that higher marital quality will be associated with higher quality father-child interactions.

\section{Research Questions}

The present study tests the systemic ecological assumption that father-child interaction is best understood as an additive process between members of the family system over time. Using hierarchical regression techniques, we first test whether earlier measures of individual sociodemographic, father, child, and mother characteristics contribute to father-child interaction at first grade net of the other characteristics in the model. Second, we test whether earlier measures of dyadic mother-child interaction quality 
and the quality of the parental marriage contribute to father-child interaction at first grade net of other characteristics in the model. Third, we test the systemic ecological assumption that family processes are not only additive but also interactive. Noting a gap in the current research base on the moderating influences of fathers and children on their mutual interaction, we focused our moderational analyses on the two-way interactions between the individual father and child characteristics in the model and hypothesized that father-child interaction will vary as a function of the interactive combination of these characteristics.

Embedded in this broad systemic ecological test are some specific hypotheses about the ways we anticipate that individual and dyadic subsystems will influence father-child interaction. For example, we hypothesized that a father's traditional parenting attitudes will be negatively related to father-child interaction, while his responsibility for childrearing will be positively related to quality father-child interaction. We further hypothesized that boys, firstborn children, and children with an easier temperament may have higher quality father-child interaction than their counterparts. Though less research has explored the association between children's social and language skills and father-child interaction quality, we tentatively hypothesize that both social skills and language skills will be positively associated with father-child interaction quality.

Next, we noted a need to disentangle contradictory findings regarding the association between maternal employment and father-child interaction. We hypothesized that the effects of maternal employment on father-child interaction will depend not only on the number of hours a mother works, but also on parents' attitudes and beliefs about maternal employment. We also raised two competing hypotheses about the association between mother-child interaction and father-child interaction. First, a complementarity hypothesis suggests that mother-child and father-child interaction will be positively correlated. Second, a compensatory hypothesis suggests that the two will be negatively correlated.

\section{Method}

\section{Participants}

The sample for this study came from the Study of Early Child Care, a comprehensive longitudinal study funded by The Eunice Kennedy Shriver National Institute of Child Health and Human Development. Researchers recruited participants from 31 hospitals in or near 10 geographic sites across the United States. Recruitment resulted in a sample of 1,364 healthy infants and their families. The sampling plan and selection are described in more detail in NICHD Early Child Care Research Network (1997). Data from mothers and children were collected when the children were 1, 6, 15, 24, 36, 54 months old and at first grade (NICHD Early Child Care Research Network, 2004). Unfortunately, data on father-child interaction were not collected from all 10 geographic sites until the second phase of data collection. For example, data regarding father's re- 
sponsibility for childrearing and his parenting beliefs were not collected until the target child's first grade school year. Further, only resident fathers were included in fatherchild interaction observations, thus the sample used for these analyses consisted of stably married, resident fathers who completed a structured interaction task with the target child at first grade $(n=586)$. Despite some of these limitations, the large scale of the study and access to individual and dyadic data regarding children, mothers, and fathers in the same family provide an opportunity to build on earlier studies that lacked a more geographically diverse sample and independent measurement.

The children in the sample were evenly divided between males and females and were primarily White, non-Hispanic (89\%). This subset of families is significantly better educated and has higher incomes when compared with the entire Study of Early Child Care sample as would be expected for a subset of stably married individuals.

\section{Measures}

Paternal education and child race. Mothers reported father education levels and child race/ethnicity during the one-month interview. Dummy codes for ethnicity were used with White non-Hispanic children as the reference group, and all other ethnicities dummy coded as 1 due to insufficient sample size in other groups.

Average paternal income. Because a father's role as income provider to the family is a predictor of his behaviors (Christiansen \& Palkovitz, 2001), we focus our analyses on the father's income rather than a measure of overall family income. The score reflects the average of all income provided by the father when the child was $6,15,24$, 36 and 54 months old to paint as clear a picture of the father's overall provider role prior to the interaction as possible. To decrease skewness and kurtosis, the natural log of non-maternal income was used.

Father childrearing beliefs. At first grade, fathers' beliefs about child-rearing were measured using 22 items from the Parental Modernity Scale of Child-rearing and Educational Beliefs (Shaefer \& Edgerton, 1985). The items were scored on a five-point Likert scale ranging from $1=$ "Strongly disagree" to $5=$ "Strongly agree." Sample items include questions such as "The most important thing to teach children is absolute obedience to whoever is in authority," and "children must be carefully trained early in life or their natural impulses will make them unmanageable." Higher scores indicate more adult-centered beliefs $(\alpha=.88)$.

Father responsibility for childrearing. When the child was in first grade, fathers rated their involvement in 16 childrearing activities (such as giving the child a bath, packing a lunch for the child, and getting up at night to attend to the child) on a 5-point proportional scale ranging from $1=$ "My partner's job" to $5=$ "My job". Higher values denote more father responsibility and less mother responsibility for childrearing activities $(\alpha=.84)$. 
Child temperament. At the 6-month visit, mothers scored their infants' overall temperament on a 3-point scale using the modified Early Infant Temperament Questionnaire (Carey \& McDevitt, 1978). Higher scores reflect a less difficult temperament ( $\alpha$ $=.81$ ). While this measure is limited because it is only available in infancy, temperament is an important transactional variable that should influence early relationship dynamics. Further, as Rothbart and Bates (2006) submit, theory would suggest that temperament is a relatively stable individual characteristic across time and situations.

Child language skills. At 54 months, children were assessed on the Preschool Language Scale-3 (PLS-3) to measure vocabulary, grammar, morphology, and language reasoning (Zimmerman, Steiner, \& Pond, 1979). The sum of the auditory and expressive communication scales was used here. Scores in this sample range from 50 to 137. Higher scores reflect a child's greater receptive and expressive communication skills.

Child social skills. When the target child was 54 months old, parents rated child cooperation, assertion, responsibility, and self control using the Social Skills Rating System (Gresham \& Elliot, 1990). Parents rated how often a behavior occurred on a scale ranging from $0=$ "Never" to $2=$ "Very often." Higher total scores represent better child social skills (Fathers' $\alpha=.86$ and mothers' $\alpha=.87$ ). Separate parent reports were used as the two were not highly correlated $(r=.37, p<.001)$.

Maternal employment. Mothers reported the total number of hours worked in a given week when the target child was 54 months old. Dummy codes were created to represent three mutually exclusive maternal employment groups: little employment (0 to 9 hours per week), part-time employment (10 to 32 hours per week), and full-time employment (33 hours or more per week). The "little employment" group was the reference group in the regression analyses.

Perceived costs of maternal employment. One month after the target infant's birth, mothers responded to the Attitude Toward Maternal Employment Questionnaire (Greenberger, Goldberg, Crawford, \& Granger, 1988). The score was composed of six items designed to measure beliefs that maternal employment is harmful to children. Sample items include "children are less likely to form a warm and secure relationship with a mother who is working full time," "children whose mothers work are more likely to be left alone and exposed to dangerous situations," and "working mothers are more likely to have children with psychological problems than mothers who do not work outside the home." Mothers' responses ranged from $1=$ "disagree very strongly" to 6 = "agree very strongly." Higher scores indicate a stronger belief that maternal employment is harmful to children's development.

Satisfaction with mother's work. At the 36-month interview, using a 5-point Likert scale mothers answered the question: "How satisfied is your husband/partner with your current work situation?" Higher scores denote fathers' greater satisfaction with 
mothers' work situation. While father-child interaction has been linked with maternal employment in previous research, we pair maternal employment hours with the father's satisfaction with maternal employment to better contextualize the role of maternal employment on father-child interaction. Though one might prefer a measure of father's satisfaction with maternal employment closer to the first grade measurement of father-child interaction, it was not available in the second phase of data collection. Hence, this measure reflects the father's attitude when the child was younger.

Mother-child dyadic positive interaction. When the child was 54 months old, mothers and children were observed in three structured interaction tasks in the laboratory. The tasks were designed to be too difficult for the 54-month-old target child to accomplish on his/her own. At a central location, well-trained observers coded the videotaped interactions for child-specific characteristics, mother-specific characteristics, and dyad-specific characteristics. The coding scheme ranged from 1 to 7 and was created based on Egeland and Hiester's (1993) teaching task rating scales (see NICHD Early Child Care Network, 2004, for more details on the specific tasks and observational codes). Inter-observer reliability estimates range from .80 to .92 .

A principal components extraction with varimax rotations was conducted to establish which items best captured the dyadic nature of the mother-child interaction. One primary factor, with an Eigenvalue of 6.99, accounted for $64 \%$ of the variance shared among the factors. Therefore, we created a simple average score based on those items with factor loadings of .50 or higher. As this factor contained items representing the child's behavior (child's experience of the session, child's affection toward the mother), the mother's behavior (mother's supportive presence), and aspects of the dyadic interaction (affective mutuality, goal-directed partnership), the composite score was labeled "mother-child dyadic positive interaction."

Marital intimacy. Fathers and mothers completed the 6-item emotional intimacy subscale of the Personal Assessment of Intimacy in Relationships when the target child was 54 months old (Schaefer \& Olson, 1981). Sample items include "My spouse/partner listens to me when I need someone to talk to," and "I feel neglected at times by my spouse/partner." Responses range from $1=$ "Strongly disagree" to $5=$ "Strongly agree." Higher scores indicate a more positive assessment of emotional intimacy and support in marriage. Both father and mother scores were kept in analyses as they were only moderately correlated ( $r=.41, p<.001$; Wives' $\alpha=.86$, husbands' $\alpha=.84$ ).

Father-child dyadic positive interaction. Positive interaction between the father and the child was assessed in the home twice, once at 54 months, and again when the child was in first grade. During the visits, the father and child participated in semistructured interaction tasks taking approximately 15 minutes to complete. The tasks were designed to be too difficult for the child to do alone, requiring the father's help and cooperation to enable the child to complete the tasks successfully. When the child was 54 months old s/he and the father were asked to build a series of chutes and ramps 
for marbles to run through, and then were invited to participate in a pretend play task with African animal families and jungle setting props. When the child was in first grade fathers and children drew a sailboat together using an etch-a-sketch toy, with each holding one knob to create the diagonal lines of the sail; participated in a geometric block activity together; and played a slap-jack card game.

All interaction tasks were designed to assess such child emotional regulation skills as the ability to inhibit inappropriate affect while attempting challenging tasks with the father's help, the ability to persist despite the difficult level of the tasks, and the child's overall affective experience of the session. They were designed to assess the father's interactional qualities such as confidence in his ability to engage the child appropriately, ability to promote child autonomy, the nature of his presence as a supportive figure ready to offer aid as he or the child might see fit. Two features of the dyad were assessed: shared affect and goal-directed partnership (see Egeland \& Heister, 1993, for more detailed definitions of all codes).

Trained observers coded videotapes of the interactions using scales ranging from 1 (Very low) to 7 (Very high) for five father items (supportive presence, respect for child's autonomy, stimulation of cognitive development, quality of assistance, and confidence), four child items (agency, negativity - reflected for the purpose of these analyses, persistence, and overall experience of session), and two dyadic items (goal-directed partnership, and affective mutuality). All tapes were coded at a central location by coders who were not acquainted with the family's history. Inter-observer reliability estimates ranged from .71 to .88 .

We created an average score of dyadic interaction quality based on the results of a principal components extraction with varimax rotation of all father, child, and dyadic observational codes. Though we expected to find multiple individual level and dyadic indicators of father-child interaction quality, after including all variables, one factor with an Eigenvalue greater than or equal to 1.0 emerged. With an Eigenvalue of 6.9, the factor accounted for $63 \%$ of the variance shared among the factors. We created a composite variable representing all observational codes loading on the factor .50 or higher. The principal components extraction indicated that a variable including father codes (supportive presence, respect for child autonomy), child codes (child experience of the session, child agency), and dyadic codes (affective mutuality, goal-directed partnership) best accounts for the shared variance among the codes. We labeled our composite variable "father-child dyadic positive interaction."

\section{Analysis Plan}

\section{Imputation of Missing Data}

We conducted multiple imputations of missing values using the EM Algorithm in SAS to remedy problems with missing values in the current sample and to estimate coefficients with the least amount of bias. The first step includes the creation of the imputation model. All terms in the analysis model were included in the imputation model 
(Schafer, 1997). Once the imputation model was created, five new imputed data sets using random variation and the EM algorithm were generated in SAS. Increasing the number of imputations decreases the amount of uncertainty due to imputation, and based on Rubin's criteria, five imputations creates the most efficient use of the EM algorithm for the amount of data missing in this sample (Schafer).

Next, regression models were fit to each imputed data set, and estimates were pooled, combining standardized coefficients across all imputations. The pooled standard error and adjusted degrees of freedom take into account uncertainty due to sampling, missingness, and imputation, creating the best estimate of the effects based on the model. Descriptive statistics for the variables used in the sample both before and after imputations are displayed in Table 1. A comparison of results showed that there were no statistically significant differences between means and standard deviations among any of the variables as a result of imputation. We note here that we did not impute missing values on the dependent variable.

\section{Regression Analyses}

OLS regressions were used to test portions of the model individually; then sets of predictors were added in blocks to test the full model. Each group of predictors was tested alone controlling for sociodemographic characteristics before inclusion in the larger model, but the coefficients did not differ substantially from those in the full model (results available on request). We note that while growth curve modeling was not possible for these analyses because father characteristics were available at only one time point, the multiple imputation procedure we employed uses full maximum likelihood estimates of all regression coefficients (the same robust parameter estimation technique that growth curve or hierarchical linear modeling techniques would use; see Schafer, 1997 for further details).

Interaction terms were first examined individually. Variables were centered for ease in the interpretation of results. Next, final models were created by entering all significant interaction terms. Post hoc tests of significant interactions were examined following Aiken and West (1991). For clarity in our models, we report only significant interaction terms.

\section{Results}

Results of full models, adding blocks of predictors cumulatively, are shown in Table 2.

\section{Sociodemographic Characteristics}

Three sociodemographic characteristics were tested in Model 1: paternal education, child ethnicity, and paternal income. High levels of paternal education and paternal income were significantly associated with father-child interaction, but adding other fam- 
ily characteristics to the model accounted for their effects. Child ethnicity was nonsignificant across all models. Sociodemographic characteristics accounted for $4 \%$ of the variance in father-child interaction.

Table 1

Means (Standard Deviations or Percentages) for Characteristics in Whole Sample Before and After Imputation

\begin{tabular}{|c|c|c|c|}
\hline Variable & $\begin{array}{c}\text { Before } \\
\text { Imputation }\end{array}$ & $\begin{array}{l}\text { Percent } \\
\text { Missing }\end{array}$ & $\begin{array}{c}\text { After } \\
\text { Imputation } \\
(\mathrm{n}=586)\end{array}$ \\
\hline
\end{tabular}

Sociodemographic

Paternal Education (1 month)

$15.31(2.52)$
$\$ 49,326(\$ 51,238)$
$522(89 \%)$

0

$15.31(2.52)$

Paternal Income (6-54 months)

$522(89 \%)$

0

$\$ 49,326(\$ 51,238)$

White, non-Hispanic (1 month)

$\begin{array}{cc}5.85(.77) & 7 \\ 58.48(13.46) & 5 \\ 2.50(.37) & 6\end{array}$

$5.88(.78)$

Dyadic Composite (54 months)

Traditional Beliefs ( $1^{\text {st }}$ grade $)$

Responsibility ( $1^{\text {st }}$ grade)

$2.50(.37)$

$58.53(13.50)$

$2.52(.37)$

\section{Child}

Boys (\%)

Firstborn (\%)

Temperament (6 months)

Language Skills (54 months)

Social Skills (M-54 months)

Social Skills (F-54months)

\section{Mother}

Full-time Work (54 months)

Part-time Work (54 months)

Sat. w/Mat. Employ (F-36 months)

Costs Mat. Employ (M-1 month)

Mother-Child Interaction

Dyadic Composite (54 months)

\section{Parental Marriage}

Wife Report (54 months)

Husband Report (54 months)

$293(50 \%)$
$253(43 \%)$
$2.66(.53)$
$105.39(17.47)$
$50.98(8.56)$
$49.94(8.47)$

6

0

$293(50 \%)$

$253(43 \%)$

$2.66(.53)$

$105.29(17.55)$

$51.00(8.56)$

49.91 (8.34)

.


Table 2

Standardized Effects of Predictors on Dyadic Father-Child Interaction at First Grade $(\mathrm{n}=586)$

\begin{tabular}{llllrr}
\multicolumn{5}{c}{ Model } & \\
\cline { 1 - 2 } 1 & 2 & 3 & 4 & 5 & Full M \\
& & & & & \\
$\mathbf{. 1 2} *$ & .02 & .02 & .01 & -.04 & -.05 \\
$\mathbf{. 1 4 * *}$ & $\mathbf{. 1 2} * *$ & $\mathbf{. 1 1} *$ & $\mathbf{. 1 1} *$ & .06 & .06 \\
.01 & .02 & .04 & .04 & .04 & .04
\end{tabular}

Sociodemographic

Paternal Education

$\begin{array}{lllllll}\text { Paternal Income (6-54 months) } & \mathbf{. 1 4} * * & \mathbf{. 1 2}^{* *} & \mathbf{. 1 1} * & \mathbf{. 1 1} * & .06 & .06 \\ \text { White, non-Hispanic } & -.01 & .02 & .04 & .04 & .04 & .04\end{array}$

Father

Dyadic Composite (54 months) -

$\begin{array}{rcccc}. \mathbf{2 7} * * * & . \mathbf{2 5} * * * & \mathbf{. 2 5} * * * & \mathbf{. 2 4} * * * & \mathbf{. 2 4} * * * \\ -. \mathbf{1 8} * * * & -. \mathbf{1 7} * * * & -. \mathbf{1 7} * * * & -. \mathbf{1 7} * * * & -. \mathbf{1 7} * * * \\ .02 & .02 & .04 & .04 & .04\end{array}$

Traditional Beliefs ( $1^{\text {st }}$ grade $)$

Responsibility $\left(1^{\text {st }}\right.$ grade)

$-$

.02

\begin{tabular}{|c|c|c|c|c|}
\hline- & -.01 & -.01 & .00 & -.01 \\
\hline- & -.03 & -.03 & -.02 & -.01 \\
\hline- & .04 & .04 & .05 & .03 \\
\hline- & $.12 * *$ & $.10 *$ & $.11 *$ & $.10 *$ \\
\hline- & .00 & .00 & .01 & .01 \\
\hline- & $.11 *$ & $.10^{*}$ & $.10^{*}$ & $.08 *$ \\
\hline
\end{tabular}

Interaction Effects

Trad. Beliefs x Social Skills

Child

Boys

Firstborn

Temperament (6 months)

Language Skills (54 months

Social Skills (M-54 months)

Social Skills (F-54 months) -

\section{Mother}

Full-Time Work (54 months)

Part-Time Work (54 months) -

Sat. w/Employ (F-36 months) -

Costs Employ (M-1 month) -

$-$

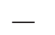

$.09 *$

$.09 *$

$.10 *$

Mother-Child Interaction

Dyadic Composite (54 months) -

Parental Marriage

Wife Report (54 months)

\begin{tabular}{llllcc}
- & - & - & - & $-.13^{*}$ &.$- .13^{*}$ \\
- & - & - & - & -.02 & -.02 \\
- & - & - & - & .07 & .07 \\
- & - & - & - & -.03 & -.03 \\
& & & & & \\
- & - & - & - & - &. $\mathbf{1 3}^{*}$ \\
& & & & & \\
- & - & - & - & - & .04 \\
- & - & - & - & - & .02 \\
- & .10 & .03 & .01 & .03 & .02 \\
.04 & .14 & .17 & .18 & .21 & .22 \\
\hline
\end{tabular}

Change in Adjusted $R^{2}$

${ }^{\text {a }}$ Median Adjusted $\boldsymbol{R}^{2}$

$* p<.05 . * * p<.01 . * * * p<.001$.

${ }^{a}$ As a result of pooling across imputations, median reports of the Adjusted $\mathrm{R}^{2}$ are listed. 


\section{Characteristics of Individuals within the System: Father and Child Contributions}

Father-child dyadic interaction at 54 months was positively related to the quality of father-child interaction across all models; earlier quality in the father-child dyad is related to subsequent quality in the same dyad. This is the largest effect in the full model, suggesting that a developmental approach to father-child interaction may be fruitful. Unfortunately, a father's responsibility for his first grader was not related to relationship quality at first grade.

Fathers' traditional childrearing beliefs were negatively related to the quality of the father-child interaction across all models; men with more adult-centered beliefs were less positively engaged with their children. The effect size estimate for fathers' traditional childrearing beliefs was the second largest of all effects in the full model. Overall, father characteristics accounted for an additional $10 \%$ of variance in the model.

The association between fathers' beliefs and dyadic interaction was moderated by fathers' earlier perceptions of children's social skills. Fathers with highly traditional childrearing beliefs who perceived their 4-1/2-year-old to be highly socially skilled were more likely to engage in positive interaction when their child was in first grade than those highly traditional fathers who rated the child low on social skills. Fathers with more child-centered beliefs appear to have better engagement regardless of perceived child social skills.

Aside from a significant association between child social skills at 54 months and father-child interaction quality at first grade, children observed to have higher language skills at 54 months were also observed to have more positive father-child interaction at first grade. However, child gender, birth order, maternal report of temperament, and maternal report of child social skills, were all non-significant. Child characteristics and the interaction between father beliefs and child social skills added another $4 \%$ of variance to the model.

\section{Maternal Employment Contexts}

In families where mothers were employed full-time when the child was 54 months old, father-child interaction quality at first grade was lower than when mothers reported little or no employment. There was no difference between families with mothers who worked part-time and mothers with little or no employment. We hypothesized that understanding maternal attitudes and beliefs about employment would further contribute to the association between maternal employment and the quality of father-child interaction at first grade, but we found no support for this hypothesis. Mothers' beliefs about the effects of maternal employment on children, and fathers' satisfaction with maternal employment were not associated with the quality of father-child interaction. Maternal employment added another $3 \%$ of variance to the model. 
Characteristics of Dyadic Subsystems: Mother-child Interaction and the Parental Marriage

The quality of mother-child interaction when the child was 54 months old was positively associated with the quality of father-child interaction when the same child was in first grade. Even after controlling for observations of the same father and 54month-old child, when a mother and her 54 month old were observed in positive interaction with one another, the same child and his or her father were more likely to engage in positive interaction by the child's first grade year. Mother-child interaction added another $2 \%$ of variance to the model.

Though the parental marriage is often associated with fathers' involvement with their children, neither husbands' reports nor wives' reports of emotional intimacy in marriage when the child was 54 months old were associated with father-child interaction at first grade.

\section{Discussion}

Guided by Doherty et al.'s model, we tested three primary systemic ecological claims about father involvement. First, we tested the assumption that to understand father-child interaction in a given family, we must consider not only a father's contributions to his interaction with his child, but also the child's and the mother's contributions to father-child interaction in the same family context. These contributions are assumed to be additive. Comparisons across components of the model using hierarchical regression techniques support the claim that individual factors specific to fathers, children, and mothers all additively contribute to father-child interaction quality at first grade. For example, the significant contributions of a father's childrearing attitudes, a child's social skills, his/her language skills, and full time maternal employment all persist in the full model. While the sociodemographic contexts of fathers' average income and education were significant independent of other characteristics in the model, father characteristics appear to account for educational contexts, and maternal employment appears to account for the effect of fathers average income contributions to the family.

Second, we tested the assumption that not only do individual characteristics of the father, child, and mother additively contribute to father-child interaction quality, but also family subsystems, such as dyadic interaction between the mother and the child, and dyadic interaction between marital partners additively contribute to father-child interaction quality. Our findings offer some support for this claim. The most compelling evidence to support the contribution of dyadic subsystems to father-child interaction comes from the finding that mother-child interaction (measured when the target child was 54 months old) is significantly associated with the quality of father-child interaction at first grade. This significant association endures even after accounting for the quality of father-child interaction when the child is 54-months-old along with all other individual and dyadic characteristics in the model. Results of the full model suggest that we understand some of the variability in father-child interaction not only by exploring 
characteristics of the father, child, and mother, but also by learning something about how the mother and same target child interact with one another. We explore specific hypotheses about this association under the section heading "Mother Characteristics."

However, our second test of the association between family subsystems and father-child interaction did not yield such compelling evidence. Though the Early Child Care Research Network found a significant relationship between husbands' reports of marital intimacy and sensitivity toward their 36-month-old in a partial sample from the NICHD Study of Early Child Care (NICHD Early Child Care Research Network, 2000), in our study representing all 10 geographic sites when the target child was in first grade, neither husbands' nor wives' reports of the quality of emotional intimacy in marriage were not significant. We note that the lack of a significant association may be due to the restricted nature of our sample. Fathers who separated or divorced over the course of the study were not observed in interactions with their children, therefore leaving the most maritally satisfied couples in our sample. Despite this limitation, it may be that couples need to drop below a threshold of satisfaction for marriage to impact father involvement. Other scholars have found that conflict in co-parenting and negativity in marriage are stronger predictors of father involvement than global reports of marital quality (McBride \& Rane, 1998), and that relational positivity and conflict are two related, but distinct constructs (Karney \& Bradbury, 1995). To understand the comparative importance of the co-parental relationship versus other individual and dyadic systemic predictors, further exploration of distinct aspects of co-parenting and marital processes would be useful.

Third, we tested the assumption that father-child interaction is best understood in a model that accounts not only for the additive effects of individual and dyadic processes, but also one that accounts for the interactive nature of family processes. Of the multitude of possible moderating influences within a given family system, we focused our attention on the ways in which individual characteristics of the father and the child might modify the quality of father-child interaction. We anticipated that different two-way combinations of father characteristics and child characteristics would provide distinct contexts for the quality of interaction. Surprisingly, only one two-way interaction was statistically significant. Although fathers' traditional beliefs about parenting were negatively associated with father-child interaction quality in first grade, this main effect was moderated by children's social skills. A father's traditional beliefs were associated with low quality interaction primarily when fathers had earlier rated their child low on social skills. This finding suggests that the quality of father-child interaction at first grade is based not only on the father's initial ideas about how a child should be raised, but also on his child's ability to cooperate, assert his or her own needs, follow social rules, and show some responsibility for his or her own actions.

The lack of support for the moderation of other father and child characteristics is puzzling. Our theoretical model would suggest that the father-child dyad functions as a unit, with each member participating in joint processes based on the other's characteristics. This was simply not supported by the majority of our statistical tests. We encourage other scholars to continue to test other possible interactions between father 
and child characteristics to help scholars understand under which interactive contexts processes in the father-child dyad are best captured. We further encourage others to explore interactive processes outside of the father-child dyad which may still influence the quality of father-child interaction not only in first grade, but also at other ages and developmental stages.

Finally, outside of support for broader theoretical notions about the systemic ecological nature of father involvement, we were also interested in filling some gaps in the current literature regarding associations between specific father, child, and mother characteristics as they pertain to the quality of father-child interaction in first grade. Below we discuss our more specific hypotheses, and suggest other directions for future research.

\section{Characteristics of Individuals within the System: Father and Child Contributions}

Little empirical support exists for the commonly held assumption that quality and quantity fathering are associated. To help fill the gap we simply asked if a significant association between responsibility for care (quantity) and father-child interaction (quality) exists. In this sample, father responsibility for childrearing was not statistically associated with the quality of father-child interaction at first grade. On one hand, our findings do not diverge from Lamb et al. (1985) who argue that responsibility is distinct from engagement; in our sample that seems to be the case. On the other hand, Lamb et al. also suggest that responsibility has the potential to create opportunities for direct engagement. One might assume that increasing opportunities for direct engagement would lead to better quality interaction between fathers and their children. We wonder: are there circumstances under which increased responsibility might increase quality in the dyad, others where it might reduce the quality of father-child interaction, and yet other circumstances where it might not be associated with increased interactional quality at all? For example, some studies of unemployed fathers show high quantities of responsibility for care when mothers enter the workforce and unemployed fathers take on new responsibilities, but low quality interactions between fathers and children, presumably because fathers were involuntarily caring for their children (Radin, 1981). We encourage others to continue considering these contexts of responsibility and father-child interaction in more depth.

We also noted a gap in research on the ways that children contribute to father-child interaction. The present study expands our understanding of children's contributions to father involvement by not only supporting the claim that children influence fathers, but also by establishing that children's social and language skills facilitate interaction in the dyad beyond fathers' own skill. Children with high receptive and expressive language skills engaged in more positive father-child interactions than did children with low skills. Earlier research on mother-child dyads demonstrated that sophisticated infant language skills allowed children to express their own needs, and also afforded mothers opportunity to respond effectively to children's needs (Bronson, 1974). The current study establishes that child language skills predict joint interactions in the fa- 
ther-child dyad as children age, and provides evidence that relations between language skills and parent-child interaction are not exclusive to mother-infant dyads. Further, child sociability has previously been linked with fathers' increased time with children, accessibility, and reported responsibility for child care (McBride et al., 2002), and now can be connected with observed quality in the father-child dyad. Together, father and child characteristics contributed the greatest amount of variance in the model, suggesting their import within the large scope of a systemic ecological perspective.

\section{Maternal Employment Contexts}

Contrary to some earlier findings, father-child interaction was less positive when mothers were employed full-time than when they engaged in little employment. Parttime maternal employment, however, was not related to father-child interaction quality. Based on observations of family systems, Almeida, Wethington, and Chandler (1999) discovered that when wives work full-time, day to day tensions from a variety of stressors spillover into the father-child relationship. We were unable to account for day-to-day tensions, but suspect that similar processes might be at work with families in our sample. We further hypothesized that accounting for parental attitudes about employment would help us understand the effects of maternal work on father-child interaction better than simply considering the number of hours mothers work per week, but our data do not support this claim. Our findings point to a strong need to understand the complexities of maternal employment as a context for father-child interaction quality.

\section{Characteristics of Dyadic Subsystems: Mother-child Interaction}

The positive association between mother-child and father-child interaction supports the systemic ecological claim that father-child interaction is associated with other dyadic level processes in families. But this association also supports the widely held hypothesis that there is a meaningful connection between mothering and fathering not only based on a mother's attitudes about father involvement or her characteristics in the co-parental relationship as previously explored, but also based on her own interaction with the same child. It is important to note that this association is significant even after controlling for father-child interaction at 54 months.

We suggested two possible hypotheses for the connection between mother-child and father-child interaction: a complementarity hypothesis and a compensatory hypothesis. Our findings support a complementarity hypothesis. The quality of interaction in the mother-child relationship is positively correlated with the quality of interaction in the father-child relationship. Based on a systemic ecological perspective, this relation may be capturing a common climate of interaction among family members in the system. This common climate may reflect the simple possibility that mothers and fathers choose mates with similar personality characteristics and similar parenting styles, or that mothers and fathers are similarly influenced by their child. It may also be that fathers and mothers glean skills by observing and modeling each other's behaviors with 
the same child. This finding continues to demonstrate that there are many more hypotheses to be explored regarding the association between mother-child and fatherchild interaction.

\section{Strengths and Limitations}

Aside from assessing the additive and interactive effects of sociodemographic, individual, and dyadic factors on father involvement, this study has two other strengths. First, it uses paternal, maternal, and observer reports where possible to minimize the effects of shared method variance present in many fathering studies (Marsiglio, et al., 2000). Second, it utilizes available longitudinal data reflecting the child's skills, mothers' characteristics, nature of dyadic mother-child interaction, and nature of the marriage in order to test the combined effect of these components on father-child interactions with their first graders. While the study accounts for some portion of the history of father-child interaction over time by including a 54-month measure of fatherchild interaction, the father's traditional childrearing beliefs and his responsibility for childrearing were not available prior to our measure of father-child interaction at first grade, thus our model is unable to account for change in these correlates of father-child interaction.

While we did not find a direct association between maternal reports of infant temperament and observed father-child relationship quality, we suggest our readers use caution when interpreting this result. An assessment of temperament taken closer to the child's first grade year may yield more accurate results. Also, mothers and fathers may perceive child temperament differently (Jones \& Parks, 2007). A father's perception of his child's temperament has been reported to be a stronger predictor of fathering than a mother's perception (Wong, Mangelsdorf, Brown, Neff, Schoppe-Sullivan, $\&$ Sokolowski, in press).

Further caution is needed in inferring causal direction in these findings. Although this study had some longitudinal components including tests of earlier father-child interaction, earlier child characteristics, earlier maternal characteristics, earlier observations of the mother-child dyad, and earlier spousal reports of the marriage, measures of the fathers' characteristics were not available prior to first grade; thus sequential order cannot be fully established.

While the families in this data set represent a range of socioeconomic and cultural backgrounds, the sample is not nationally representative. For example, in the entire sample children from ethnic minority groups are somewhat underrepresented. Mean household income and maternal education are somewhat higher than the U.S. average, though sample families were more likely to receive public assistance than U.S. families in general (NICHD Early Child Care Research Network, 2001). Though the sample size of 586 families allowed for enough power to test a complicated model, using this smaller subsample of stably married families magnified the demographic limitations of this sample, hence the results cannot be safely generalized to other groups. Because Doherty et al. (1998) suggest that ecological influences such as family structure, 
the father's residential status, his biological versus step-father status, and ethnicity could well affect father-child interaction quality, further studies able to explore these contexts of systemic ecological processes will provide new important understanding of the way that children, fathers, and mothers contribute to quality father-child interaction.

\section{References}

Allen, S.M., \& Hawkins, A.J. (1999). Maternal gatekeeping: Mothers' beliefs and behaviors that inhibit greater father involvement in family work. Journal of Marriage and the Family, 61, 199-212.

Barnett, R.C., \& Gareis, K. (2007). Shift work, parenting behaviors, and children's socioemotional well-being: A within family study. Journal of Family Issues, 28 (6), 727-748.

Beitel, A.H., \& Parke, R.D. (1998). Paternal involvement in infancy: The role of maternal and paternal attitudes. Journal of Family Psychology, 12, 268-288.

Bell, R.Q. (1968). A reinterpretation of the direction of effects in studies of socialization. Psychological Review, 75, 81-95.

Belsky, J. (1984). The determinants of parenting: A process model. Child Development, 55(1), 83-96.

Belsky, J. (1999). Quantity of nonmaternal care and boys' problem behavior/adjustment at ages 3 and 5: Exploring the mediating role of parenting. Psychiatry: Interpersonal and Biological Processes, 62, 1-20.

Bonney, J.F., Kelley, M.L., \& Levant, R.F. (1999). A model of fathers' behavioral involvement in child care in dual-career families. Journal of Family Psychology, 13, 401-415.

Bronson, W.C. (1974). Mother-toddler interaction: A perspective on studying the development of competence. Merrill-Palmer Quarterly, 20, 275-301.

Cabrera, N., Fitzgerald, H.E., Bradley, R.H., \& Roggman, L. (2007). Modeling the dynamics of paternal influences on children over the life course. Applied Developmental Science, 11(4), 185-189.

Carey, W.B., \& McDevitt, S.C. (1978). Revision of the infant temperament questionnaire. Pediatrics, 61, 735-739.

Christiansen, S.L., \& Palkovitz, R. (2001). Why the "good provider" role still matters: Providing as a form of paternal involvement. Journal of Family Issues, 22, 84-106.

Clarke-Stewart, K.A., Gruber, C.P., \& Fitzgerald, L.M. (1994). Children at home and in day care. Hillsdale, NJ: Erlbaum.

Cummings, E.M., Goeke-Morey, M.C., \& Raymond, J. (2004). Fathers in family context: Effects of marital quality and marital conflict. In. M. Lamb (Ed.), The role of the rather in child development (4th ed., pp. 196-221). New York: Wiley.

Doherty, W.J., Kouneski, E.F., \& Erickson, M.F. (1998). Responsible fathering: An overview and conceptual framework. Journal of Marriage and the Family, 60, 277-292.

Egeland, B., \& Hiester, M. (1993). Teaching task rating scales. Institute of Child Development, University of Minnesota.

Fagan, J., \& Barnett, M. (2003). The relationship between maternal gatekeeping, paternal competence, mothers' attitudes about the father role, and father involvement. Journal of Family Issues, 24, 1020-1043. 
Gaertner, B.M., Spinrad, T.L., Eisenberg, N., \& Greving, K.A. (2007). Parental childrearing attitudes as correlates of father involvement during infancy. Journal of Marriage and Family, 69(4), 962-976.

Greenberger, E., Goldberg, W.A., Crawford, T.J., \& Granger, J. (1988). Beliefs about the consequences of maternal employment for children. Psychology of Women Quarterly, 12, 35-59.

Gresham, F.M., \& Elliott, S.N. (1990). The social skills rating system. Circle Pines, MN: American Guidance Service.

Grych, J.H., \& Clark, R. (1999). Maternal employment and development of the father-infant relationship in the first year. Developmental Psychology, 35, 893-903.

Jones, C., \& Parks, P. (2007). Mother-, father-, and examiner-reported temperament across the first year of life. Research in Nursing \& Health, 6, 183-189.

Kelley, M.L., Smith, T.S., \& Green, A.P. (1998). Importance of fathers' parenting to AfricanAmerican toddlers' social and cognitive development. Infant Behavior \& Development, 21, 733-744.

Lamb, M.E., Pleck, J.H., Charnov, E.L., \& Levine, J.A. (1985). Paternal behavior in humans. American Zoologist, 25, 883-894.

Levy-Shiff, R. (1994). Individual and contextual correlates of marital change across the transition to parenthood. Developmental Psychology, 30, 591-601.

Marsiglio, W., Amato, P., Day, R.D., \& Lamb, M.E. (2000). Scholarship on fatherhood in the 1990's and beyond. Journal of Marriage and the Family, 62, 1173-1191.

McBride, B.A., \& Rane, T.R. (1998). Parenting alliance as a predictor of father involvement: An exploratory study. Family Relations, 47, 229-236.

McBride, B.A., Schoppe, S.J., \& Rane, T.R. (2002). Child characteristics, parenting stress, and parental involvement: Fathers versus mothers. Journal of Marriage and Family, 64, 9981011.

NICHD Early Child Care Research Network. (1997). Familial factors associated with the characteristics of nonmaternal care for infants. Journal of Marriage and Family, 59, 389-408.

NICHD Early Child Care Research Network. (2000). Factors associated with fathers' caregiving activities and sensitivity with young children. Journal of Family Psychology, 14, 200219.

NICHD Early Child Care Research Network. (2001). Nonmaternal care and family factors in early development: An overview of the NICHD Study of Early Child Care. Applied Developmental Psychology, 22, 457-492.

NICHD Early Child Care Research Network. (2004). Fathers' and mothers' parenting behavior and beliefs as predictors of children's social adjustment in the transition to school. Journal of Family Psychology, 18(4), 628-638.

Palkovitz, R. (1984). Parental attitudes and fathers' interactions with their five-month-old infants. Developmental Psychology, 20, 1054-1060.

Palkovitz, R., Marks, L., Appleby, D., \& Holmes, E.K. (2003). Parenting and adult development: Contexts, processes and products of intergenerational relationships. In L. Kuczynski (Ed.), The handbook of dynamics in parent-child relationships (pp. 307-323). Thousand Oaks, CA: Sage Publications.

Parke, R.D. (2002). Fathers and families. In M. Bornstein (Ed.), Handbook of parenting (Volume 3: Being and becoming a parent, pp. 27-74). Hillsdale, NJ: Lawrence Erlbaum.

Pleck, J.H., \& Masciadrelli, B.P. (2004). Paternal involvement by U.S. residential fathers: Levels, sources, and consequences. In M.E. Lamb (Ed.), The role of the father in child development ( $4^{\text {th }}$ ed., pp. 222-271). Hoboken, NJ: Wiley. 
Price, J. (2008). Parent-child quality time: Does birth order matter? Journal of Human Resources, 43(1), 240-265.

Radloff, L.S. (1977). The CES-D scale: A self report depression scale for research in general population. Applied Psychological Measurement, 1, 385-401.

Rothbart, M.K., \& Bates, J.E. (2006). Temperament. In W. Damon, R. Lerner, \& N. Eisenberg (Eds.), Handbook of child psychology, Sixth edition: Social and emotional personality development (Vol. 3, pp. 99-106). New York: Wiley.

Schaefer, M.T., \& Olson, D.H. (1981). Assessing intimacy: The PAIR inventory. Journal of Marital and Family Therapy, 7(1), 640-653.

Schafer, J.L. (1997). Analysis of incomplete multivariate data. London: Chapman \& Hall.

Schoppe-Sullivan, S.J., Mangelsdorf, S.C., Brown, G.L., \& Sokolowski, M.S. (2007). Goodness-of-fit in family context: Infant temperament, marital quality, and early coparenting behavior. Infant Behavior \& Development, 30, 82-96.

Shaefer, E.S., \& Edgerton, M. (1985). Parent and child correlates of parental modernity. In I.E. Sigel (Ed.), Parental belief systems (pp. 287-318). Hillsdale, NJ: Lawrence Erlbaum.

Wong, M.S., Mangelsdorf, S.C., Brown, G.L., Neff, C., Schoppe-Sullivan, S.J., \& Sokolowski, M.S. (in press). Antecedents of mother- and father-infant attachment: Infant temperament, beliefs about paternal roles, and marital quality. Journal of Family Psychology.

Zimmerman, I.L., Steiner, V.G. \& Pond, R.E. (1979). Preschool language scale. The Psychological Corporation, San Antonio, TX. 
Reproduced with permission of the copyright owner. Further reproduction prohibited without permission. 